\title{
Growth of Secure Messaging Through a Patient Portal as a Form of Outpatient Interaction across Clinical Specialties
}

\author{
R.M. Cronin 1,2,3; S.E. Davis ${ }^{1}$; J.A. Shenson"; Q. Chen ${ }^{1,5}$; S.T. Rosenbloom¹,2,3; G.P. Jackson ${ }^{1,3,6}$ \\ ${ }^{1}$ Vanderbilt University Medical Center Department of Biomedical Informatics, Nashville, Tennessee; \\ ${ }^{2}$ Vanderbilt University Medical Center Department of Medicine, Nashville, Tennessee; \\ ${ }^{3}$ Vanderbilt University Medical Center Department of Pediatrics, Nashville, Tennessee; \\ ${ }^{4}$ Vanderbilt University Medical Center School of Medicine, Nashville, Tennessee; \\ ${ }^{5}$ Vanderbilt University Medical Center Department of Biostatistics, Nashville, Tennessee; \\ ${ }^{6}$ Vanderbilt University Medical Center Department of Pediatric Surgery, Nashville, Tennessee;
}

\section{Keywords}

Patient portal, secure messaging, patient engagement, consumer health informatics

\section{Summary}

Objective: Patient portals are online applications that allow patients to interact with healthcare organizations. Portal adoption is increasing, and secure messaging between patients and healthcare providers is an emerging form of outpatient interaction. Research about portals and messaging has focused on medical specialties. We characterized adoption of secure messaging and the contribution of messaging to outpatient interactions across diverse clinical specialties after broad portal deployment.

Methods: This retrospective cohort study at Vanderbilt University Medical Center examined use of patient-initiated secure messages and clinic visits in the three years following full deployment of a patient portal across adult and pediatric specialties. We measured the proportion of outpatient interactions (i.e., messages plus clinic visits) conducted through secure messaging by specialty over time. Generalized estimating equations measured the likelihood of message-based versus clinic outpatient interaction across clinical specialties.

Results : Over the study period, 2,422,114 clinic visits occurred, and 82,159 unique portal users initiated 948,428 messages to 1,924 recipients. Medicine participated in the most message exchanges $(742,454$ messages; $78.3 \%$ of all messages sent), followed by surgery $(84,001 ; 8.9 \%)$ and obstetrics/gynecology $(53,424 ; 5.6 \%)$. The proportion of outpatient interaction through messaging increased from $12.9 \%$ in 2008 to $33.0 \%$ in 2009 and $39.8 \%$ in 2010 ( $p<0.001$ ). Medicine had the highest proportion of outpatient interaction conducted through messaging in 2008 (23.3\% of outpatient interactions in medicine). By 2010, this proportion was highest for obstetrics/gynecology $(83.4 \%)$, dermatology $(71.6 \%)$, and medicine $(56.7 \%)$. Growth in likelihood of message-based interaction was greater for anesthesiology, dermatology, obstetrics/gynecology, pediatrics, and psychiatry than for medicine $(p<0.001)$.

Conclusions: This study demonstrates rapid adoption of secure messaging across diverse clinical specialties, with messaging interactions exceeding face-to-face clinic visits for some specialties. As patient portal and secure messaging adoption increase beyond medicine and primary care, research is needed to understand the implications for provider workload and patient care. 


\section{Correspondence to:}

Robert M. Cronin

Department of Biomedical Informatics Vanderbilt University Medical Center

2525 West End Blvd., Suite 1475

Nashville, TN, 37232, USA

E-mail: robert.cronin@vanderbilt.edu
Appl Clin Inform 2015; 6: 288-304

http://dx.doi.org/10.4338/ACl-2014-12-RA-0117

received: December 19, 2014

accepted: March 3, 2015

published: April 29, 2015

Citation: Cronin RM, Davis SE, Shenson JA, Chen Q, Rosenbloom ST, Jackson GP. Growth of secure messaging through a patient portal as a form of outpatient interaction across clinical specialties. Appl Clin Inf 2015; 6: 288-304

http://dx.doi.org/10.4338/ACl-2014-12-RA-0117 


\section{Introduction}

Patient portals are web-based applications that enable patients to interact with their health information, healthcare systems, and healthcare providers [1-3]. Since the late 1990s, hundreds of institutions have implemented patient portals [4-18], with increasing adoption driven by the Affordable Care Act and Meaningful Use criteria in the United States (US) [19] and The Power of Information strategy initiated by the National Health Services (NHS) in the United Kingdom (UK) [20-22]. Use of patient portals has been shown to increase satisfaction with care, enhance communication between patients and providers, expand access to health information, and improve clinical outcomes for patients with selected diseases [23-30]. Studies of portal interventions report improved glycemic control in diabetes, reduced symptoms in patients with attention deficit hyperactivity disorders, and improved adherence to medications [31-38].

Patient portals have been implemented in diverse settings including large academic medical centers [34, 38-43], community practices [44], adult and pediatric primary care [45, 46], and specialty care $[35,36]$. Most studies of patient portals, however, have been conducted in primary care or medical subspecialty care of chronic diseases [38, 46-49]. Two recent systematic reviews of over 100 studies of the effectiveness of patient portals $[6,10]$ revealed only three studies exploring portal use outside of primary care or medical specialties [50-52]. As portal adoption increases, little is known whether and how specialties outside of medicine will use this technology.

Secure patient-provider messaging is one of the most popular functions of patient portals [32, 46, 53 , 54]. Secure messaging is a function that can be attributed to a particular clinical specialty, namely, the specialty of the provider exchanging messages with a patient. The amount of messaging done by different clinical specialties is important because prior research has shown that clinical care is delivered through portal message exchanges [36, 55]. For example, patients may report new problems, and secure messages may facilitate further evaluation and treatment [56]. Thus, messaging within a patient portal is more than a new communication modality to support administrative tasks. Instead, portal messaging can be considered an evolving form of outpatient interaction through which healthcare is delivered. A recent systematic review demonstrated that online communication was time-saving and more efficient in managing patient care, facilitated uptake of preventive care services, and showed a small improvement in adherence with medication and clinic attendance [6]. Clinical specialties that adopt secure messaging may, in fact, increase the amount of care they provide. Policies and procedures for use of secure messaging are presented in Meaningful Use criteria in the US and NHS criteria for patient access to electronic records in the UK [19-21]. As more countries adopt electronic means of delivering health care directly to patients, secure messaging may emerge as a common form of outpatient care delivery.

\section{Objectives}

We characterized the adoption of secure messaging in a patient portal across clinical specialties and determined the degree to which secure messaging contributed to the volume of outpatient interactions in a healthcare system in the three years after deployment of a patient portal throughout a full range of adult and pediatric clinical specialties. We also compared the volumes of secure messaging use relative to outpatient encounters (i.e., clinic visits) over time. Prior studies of patient portals and secure messaging have focused almost exclusively on implementations in primary care or selected medical specialties $[10,15]$. This paper reports the adoption of secure messaging after comprehensive portal deployment across diverse clinical specialties and the contributions of messaging to outpatient interactions by specialty. 


\section{Methods}

\subsection{Setting}

This study was conducted at Vanderbilt University Medical Center (VUMC), a private, non-profit institution that provides primary and regional referral care to over 500,000 patients annually. VUMC is located in middle Tennessee and serves both adults and children with over 900 inpatient beds, 50,000 inpatient admissions, and over 1 million outpatient visits per year.

VUMC launched a patient portal called My Health at Vanderbilt (MHAV) in 2005 and incrementally implemented the portal throughout the clinical enterprise. A physician champion introduced MHAV to providers, and technical support staff was available to patients, physicians, and staff as the portal was introduced in individual clinical units. MHAV was promoted to patients through flyers posted in outpatient clinics. This process was repeated, beginning in adult primary care, and then extending to adult and pediatric specialties. Specific policies and procedures that were developed to enhance patient and provider adoption have been published elsewhere [57]. MHAV patient portal is available to all patients who receive medical care at VUMC. Accounts for pediatric patients and their parents or guardians were implemented in 2007. MHAV provides a suite of common patient portal functions including access to selected portions of the electronic medical record, appointment scheduling, secure messaging with healthcare providers, account and bill management, and delivery of personalized health information [57,58]; all of these functions were fully operational by 2008. MHAV currently has over 293,000 registered users, including more than 19,000 pediatric accounts, with over 255,000 logins per month.

\subsection{Study Population}

We examined all outpatient interactions at VUMC between January 1, 2008 and December 31, 2010. This time period was chosen to examine the initial usage patterns after full deployment of MHAV throughout both adult and pediatric specialties. We defined an outpatient interaction as either a traditional outpatient clinic visit or a MHAV message thread. Message threads are collections of related messages exchanged between MHAV users and VUMC healthcare providers (i.e., initial message and all replies). MHAV users consist of VUMC patients who have registered for MHAV; individuals whom a patient designates to access MHAV on their behalf, termed delegates; and, parents or guardians who have access to their children's health information through MHAV, called surrogates.

We excluded message threads and clinic visits which involved multiple specialties or did not involve one of the main clinical specialties, such as physical therapy, radiological imaging, and laboratory appointments. We also excluded semi-automated and purely administrative messages, such as notifications for prescription refills. This study was approved by the VUMC Institutional Review Board.

\subsection{Measures}

For all VUMC outpatient clinic encounters during the study period, we recorded the encounter date; the age, sex, and race of the patient; and the clinical specialty in which the encounter took place. The research team assigned clinics to one of eight clinical specialties that reflected the departmental organization at VUMC: anesthesiology, dermatology, medicine, obstetrics/gynecology, ophthalmology, pediatrics, psychiatry, and surgery. Each specialty consisted of all relevant subspecialty divisions. For example, medicine included general internal medicine and subspecialties such as cardiology, endocrinology, and gastroenterology; surgery included general surgery as well as subspecialties such as orthopedic surgery, neurosurgery, and cardiothoracic surgery. Multidisciplinary clinics involving more than one specialty were excluded from analysis.

For each message thread, we determined the message date, role of the message sender (i.e., self, delegate, or surrogate), receiving VUMC provider, and demographics of the patient about whom the message was sent, including age at the time of thread initiation, sex, and race. The clinical specialty for each message thread was determined by the specialty of the VUMC recipient. Within MHAV, messages are directed to provider or specialty-based message baskets, message inboxes for providers, 
specialty units, or clinical functions. These message baskets are typically managed by clinical care teams, which may include physicians, nurses, administrative assistants, and allied health professionals within the same division, department, or other clinical unit $[59,60]$.

Individual providers are not required to use MHAV, nor are compensation models, which vary widely both across and within departments, affected by portal usage. Each clinical unit handles incoming messages with a process tailored to specialty workflow and provider preferences. Some clinicians answer their own messages while others utilize support staff for message triage and responses. Messages baskets are created to represent individual providers, groups of providers, or support staff groups as dictated by workflow needs of the clinical unit. This flexible approach was designed to encourage provider adoption and to allow each specialty to provide secure messaging in a manner that best suits their needs.

The research team assigned each MHAV message basket to one of the eight specialty categories enumerated above. Multidisciplinary and administrative VUMC message baskets that could not be assigned to a single specialty were excluded.

\subsection{Analysis}

We calculated the total number of message threads, patients using messaging, recipient message baskets, and outpatient clinical encounters for each month of the study period. We constructed descriptive distributions and summary statistics of patient demographics for outpatient interactions for both outpatient clinic encounters and MHAV messages. Continuous variables were summarized with medians and inter-quartile ranges. Categorical variables were summarized as counts and frequencies. To accommodate the correlation within the same patient, generalized estimating equations with logit link modeled outpatient interaction type. We explored differences in messaging usage by specialty, controlling for age, sex, race, and time of the initial message in months since beginning of the study period. We interacted month and specialty to assess changes in messaging patterns by specialty over time. In our model, continuous age was flexibly fit using a restricted cubic spline with four knots. All analyses were conducted in R version 3.0.1 and models were fit using the geeM package [61].

\section{Results}

During the study period, 960,181 message threads were initiated and 2,654,707 outpatient clinic encounters occurred. We excluded 11,753 message threads (1.2\%) and 232,593 (9.6\%) clinic visits that involved multiple specialties. After exclusions, the analysis included a total of 948,428 secure message threads from 82,159 unique MHAV users to 1,924 different VUMC provider recipients and $2,422,114$ outpatient clinic encounters in 487 VUMC clinics. The numbers of users registered for MHAV were 68,850 in 2008, 99,434 in 2009, and 127,160 in 2010.

Table 1 provides a summary of the patient demographics for these outpatient interactions. The distributions of the demographic variables among patients using messaging were different from those observed among patients involved in outpatient clinic encounters. The patient population was predominantly Caucasian, with more females than males and a median age of 46 years for outpatient encounters and 50 years for message threads.

The number of outpatient clinic visits per year fluctuated from 732,967 in 2008 to 723,154 in 2009 and 733,400 in 2010. VUMC employed approximately 2100 to 2900 faculty during this time period. The number of message threads per year increased from 108,121 in 2008 to 355,933 in 2009 and 484,374 in 2010. The number of unique portal users participating in messaging increased from 21,694 in 2008 to 51,743 in 2009 and 66,569 in 2010. The number of provider message baskets receiving portal messages also grew from 938 in 2008 to 1,311 in 2009 and 1,524 in 2010. Monthly changes in the number of patients using messaging, number of message threads, number of message recipients, and number of outpatient clinic visits are presented in $>$ Figure 1.

- Figure 2 presents the monthly distribution of outpatient interactions by type and specialty. Medicine used portal messaging more than other specialties during the study period, participating in 82,081 message threads (75.9\% of all message threads) in $2008,281,021$ (79.0\%) in 2009, and 
$379,352(78.3 \%)$ in 2010. Surgical specialists were the second most frequent users of secure messaging, contributing to 12,070 message threads (11.2\%) in $2008,31,437$ (8.8\%) in 2009 , and 40,494 $(8.4 \%)$ in 2010. Obstetrics and gynecology providers were involved in 6,414 message threads (5.9\%) in $2008,19,348(5.4 \%)$ in 2009 , and $27,662(5.7 \%)$ in 2010.

Over the study period, messaging accounted for $34.0 \%$ of outpatient interactions (i.e., clinic visits plus message threads), with the proportion of interactions occurring through secure messaging increasing from $12.9 \%$ in 2008 to $33.0 \%$ in 2009 and $39.8 \%$ in 2010 . As presented in $>$ Figure 3, among all specialties, medicine had the highest proportion and probability of message-based interactions initially (19.7\% of all outpatient interactions for medicine), but obstetrics/gynecology and dermatology surpassed medicine after 15 and 21 months, respectively. At the end of the study period, the specialties with the highest probabilities of using messaging were obstetrics/gynecology ( $90.3 \%)$, followed by dermatology (84.4\%), medicine (57.7\%) and anesthesiology (56.7\%); whereas ophthalmology had the lowest probability (4.5\%). Pediatrics and psychiatry initially conducted a small proportion of outpatient interactions through messaging (2.0\% and $1.6 \%$ respectively), but increased the proportion of interactions conducted through messages by the end of the study to $17.1 \%$ and $20.4 \%$, respectively. Ophthalmology used messaging the least overall and did not experience a large increase in adoption of messaging as a proportion of all interactions (2.1\% to $4.5 \%)$. However, ophthalmology did show an increase in overall number of message threads, from 9,600 in 2008 to 28,800 in 2010.

Initially, anesthesiology had the highest odds of using messaging versus clinic visits for outpatient interaction as compared to medicine (Odds Ratio (OR): 0.35 , 95\% Confidence Interval (CI): 0.28-0.43), while ophthalmology had the lowest (OR: 0.07, 95\% CI: 0.06-0.08) ( Table 2). The specialties with largest monthly increase in the odds of using messaging versus clinic visits for outpatient interaction relative to medicine were obstetrics/gynecology and dermatology (OR: 1.09, 95\% CI: 1.09-1.10). Surgery (OR 0.99, 95\% CI: 0.99-0.99) and ophthalmology (OR 0.98, 95\% CI: 0.97-0.98) showed a decrease in the odds of using messaging relative to medicine, but still had an absolute increase the proportion of outpatient interaction done through messaging.

\section{Discussion}

This study demonstrates widespread adoption of secure messaging through a patient portal and growth in the use of secure messaging as a form of outpatient interaction in the three-year period after deployment of a patient portal throughout adult and pediatric specialties. Notably, these changes held across a spectrum of clinical specialties, not just in primary care or medical specialties. During our study period, the total number of message threads increased by a factor of four, and the number of unique patients sending messages increased by a factor of three. The remarkable growth in use of secure messaging seen at our institution is consistent with studies documenting increasing adoption of messaging and consumer demand $[62,63]$. In coming years, portal adoption by health systems and use by patients and their providers are likely to continue to grow. Meaningful Use Stage 2 in the US requires providers to use secure electronic messaging with patients [64]. The NHS in the UK established a commitment to give patients access to their health records [21], and the Royal College of General Practitioners established a guide to achieve that commitment, which includes secure electronic messaging [20]. Similar regulations are likely to continue to be deployed worldwide leading to an increase in portal use and adoption, driven both by these regulatory requirements and consumer demand. Our experience with uptake of secure messaging across specialties in the initial years after widespread deployment of a patient portal may be particularly relevant in 2015 as portal implementation accelerates with the transition from Meaningful Use incentives to penalties [65]. Hospital administrators, department chairs, and practicing clinicians must prepare for the impact of secure messaging on clinical activities.

To our knowledge, this study is one of the first to analyze messaging use as compared to outpatient clinic encounters, and the first to examine messaging use on a comprehensive specialty-specific basis. We compared messaging use to clinic encounters rather than alternative communication modalities in part because our research team viewed secure message threads as robust clinical encounters rather than simple communications. MHAV registration was initially encouraged in the 
VUMC outpatient clinics, and we speculated that messaging volumes might be affected by the size or growth of the outpatient population, as well as the specialty of the provider. We observed that while the number of outpatient clinic encounters remained relatively stable during the study period, the proportion of outpatient interactions across all specialties that occurred through messages increased from $12.9 \%$ in 2008 to $39.8 \%$ in 2010 . In 2008, all specialties were more likely to use traditional clinic encounters than portal messaging for outpatient interaction. By 2010, providers in obstetrics/gynecology, dermatology, anesthesiology, and medicine were more likely to use portal messaging than clinic encounters for outpatient interaction.

This marked rise in proportion of outpatient interaction done through messaging may suggest a shift in how providers are delivering clinical care. Some studies have shown that messaging may replace or increase the number of outpatient office visits, telephone calls or emails; other studies have suggested that alternative forms of interaction don't change with the introduction of portal messaging $[6,12,15,17,18,35,66-71]$. As this study only considered the comparison to office visits, the observed changes could reflect a large scale substitution of telephone calls with messaging. More likely, however, patients and providers are finding new uses for messaging, such as discussing minor concerns or questions that the patient might otherwise believe are not urgent enough to warrant a phone call or office visit. It will be vital that future research characterizes the type and value of care delivered through messaging and the contributions of messaging to physician workload in an already time-taxed environment. Subsequent understanding of messaging usage may guide models for reimbursement of providers. Several proposals for compensating online care have been developed, including billing codes for transition of care and tele-health services [72], but few payers reimburse for this type of care.

Most published studies about patient portals and secure messaging describe their use in the primary care or chronic disease management settings [4-10]. In contrast, this study evaluated use of the messaging function by a wide variety of specialty providers. Previous work has shown that messaging use by patients is more prevalent when providers encourage use of the patient portal [73] and that hospital staff resistance is a barrier to patient use of secure messaging [54]. At VUMC, the initial physician champions of our patient portal were internal medicine and primary care specialists. As such, it was expected that medical specialties would be more frequent users of the portal and messaging functions. However, the adoption of messaging as a form of outpatient interaction increased significantly more rapidly in anesthesiology, dermatology, obstetrics/gynecology, pediatrics, and psychiatry than in medicine. Furthermore, the four specialties that became more likely to interact with patients through online messaging instead of in person are very diverse. Obstetrics/gynecology and medicine both provide primary care, while dermatology interactions are often episodic, and anesthesiologists deliver primarily acute care with some chronic pain follow-up. Surgical specialists, who predominately provide acute or episodic care, also contributed significantly to message thread volume across the institution. Many of these providers may have only short-term relationships with patients in the perioperative period. However, procedural specialties, like surgery, anesthesiology, and dermatology, may benefit the most from using secure messaging, especially for follow-up. A secure message is an easy way to communicate benign pathology results and subsequent plans. Postprocedural care is often included in a single fee for a procedure. Follow-up done online can make available time for revenue-generating new consultations in the outpatient clinics. Surgical providers have requested the transmission of photographs through MHAV to facilitate post-operative followup, but this functionality is not currently available.

Pediatrics and psychiatry both had very low likelihood of using messages for patient interactions in 2008, but demonstrated rapid adoption over the next two years. MHAV accounts for children only become available in 2007, which might explain the initial low usage in 2008. Psychiatric medical records are stored in a separate information system because of privacy concerns, and this separation may have made it less likely for providers to encourage messaging through MHAV. Many studies have noted a willingness of patients to communicate sensitive and psychosocial information through portal messaging [54, 71], and thus, in this study, initial resistance may have been overcome by patients' desires to use messaging. Ophthalmology, on the other hand, exhibited low levels of messaging adoption, with the increase in overall number of messages over time associated with a corresponding increase in outpatient clinic encounters at our institution. 
This study has several limitations. First, we have data from a single medical center with a locallydeveloped patient portal. Although MHAV was one of the early patient portals and had been in operation for several years before these data were collected, its features along with the unique policies and procedures of VUMC may limit the generalizability of these findings [57]. Second, the study was conducted only one year after MHAV accounts became available for children. Thus the observed usage of MHAV messaging with pediatric providers may reflect early adopter behavior.

This study explores only a single function of the patient portal, namely, messaging. We chose this function because we know that care is delivered through messages in our portal [56], and this function, unlike administrative tasks, can be linked directly to a particular specialty. Usage of messaging can also be adjusted for changes in institutional outpatient encounter volumes. The specialty-dependent use of other portal functions may differ and would likely be difficult to measure. Our analysis only included message threads initiated by patients to ensure that patients were actively engaged in the messaging interaction. Our analysis may, as a result, underestimate the total activity that occurred through messaging in the portal. Some portal messages such as prescription refill reminders are semi-automated and may not involve active patient or provider engagement in the interaction; these were not included in this study. In addition, we attributed portal communications to the initial specialty contacted by a patient and did not account for transfers of messages to other clinical specialties in subsequent inter-departmental messaging. We assumed that the specialty contacted by the patient through MHAV was actively involved in the interaction, even if only to make a referral. The distributions of specialty usage observed in this study may not fully reflect the specialties involved in the message exchanges. At worst, our study likely underestimates the total volume of activity and the specialties involved in communications conducted in the portal.

This study reported only message volumes, but did not examine the clinical nature of the message exchanges. Thus, we do not know what proportion of messages contained simple questions, such as a request for a prescription refill, versus complex clinical communications, such as reports of new symptoms or side effects of treatment. Purely administrative and semi-automated messages, such as those sent for medication refills, were excluded from this study. One prior study examining the content of early messages sent through MHAV showed rich communications that included discussions of diagnoses, medications, and treatments, with many messages containing information about more than one topic [56]. Our ongoing research projects are examining the nature of secure messaging across specialties and mapping message content to taxonomies of consumer health information needs and codes used for reimbursement.

In our statistical analysis, the messaging data contained unique patient identifiers, but the outpatient encounter data set did not. Therefore, we clustered records for message threads associated with the same patient, but could not do so for outpatient encounters. The unaccounted correlations involving the same patient, which could be within outpatient encounters or between clinic encounters and messages, would affect the estimated standard errors. However, given the large sample size and high level of significance in the observed p-values, our findings are unlikely to be affected by this limitation.

Finally, our study does not include an analysis of other common forms of outpatient interaction, such as telephone calls and email exchanges. The effects on telephone call volumes are an important consideration in evaluating the impact of secure messaging. Reviews have shown that the relationship between online patient-provider messaging and telephone calls is complex $[6,15]$, with some studies showing an increase in telephone calls with the introduction of secure messaging [17, 68], some demonstrating an increase in telephone calls with a decrease in office visits [12,67], some showing no change [36,69-71], and others showing a decrease in telephone calls [18]. Most of these studies were done in internal medicine groups or medical subspecialty clinics, not for a patient portal widely deployed across diverse practice groups in a large academic medical center. At VUMC, telephone interactions are not systematically recorded, and call management varies widely across specialties. Thus, the effects of secure messaging on telephone call volumes could not be evaluated in our study. With introduction of our patient portal and the messaging function, email interactions were strongly discouraged by our institution and were not expected to contribute significantly to outpatient interactions. 


\section{Conclusions}

This study provides evidence that after patient portal deployment, adoption of secure messaging can increase markedly in a short period of time, not just in primary care or medical disciplines, but across a wide variety of clinical specialties. We also showed that portal messaging use grew to contribute significantly to outpatient interactions at our institution. In several specialties, messaging interactions exceeded traditional face-to-face outpatient encounters. As organizations across the world adopt patient portals in response to consumer demands and regulatory requirements, they might expect to observe similar trends. How much and what types of interactions through patient portals constitute "Meaningful Use" or provide patients with adequate information to promote health will be important concerns in the coming years. Primary care and medical specialties predominate both in the research involving patient portals and in regulatory bodies that govern their use. We suspect that patient portals and secure messaging may be used to enhance communications and to deliver patient care in distinctive ways by different specialties. Additional research is needed to understand the types of care delivered through patient portals, the effectiveness of such care, and the workload implications for healthcare teams across clinical specialties.

\section{Clinical Relevance Statement}

Many organizations are currently at early stages of adopting patient portals to consumer demands or achieve regulatory requirements, such as Meaningful Use criteria in the United States and The Power of Information strategy in the United Kingdom. Our research describes the sizeable growth of messaging that might be expected in the first few years after widespread deployment of a patient portal to adult and pediatric specialties. Therefore, we believe this manuscript will be of interest to a broad range of clinical practitioners and hospital administrators as their institutions implement patient portals and consider the implications for provider workload and patient care.

\section{Conflict of Interest}

Gretchen Jackson reports salary support from funding provided to VUMC by West Health for projects not related to the submitted work. All other authors have no reported conflicts of interest related to the research.

\section{Human Subjects Protections}

The VUMC Institutional Review Board (IRB) approved this study. The study was performed in compliance with the World Medical Association Declaration of Helsinki on Ethical Principles for Medical Research Involving Human Subjects. Waiver of consent was granted by the IRB for this study involving no more than minimal risk and not adversely affecting the rights and the welfare of relevant individuals.

\section{Acknowledgements}

Robert Cronin and Sharon Davis were supported by the 5T15LM007450-12 training grant from the National Library of Medicine. 


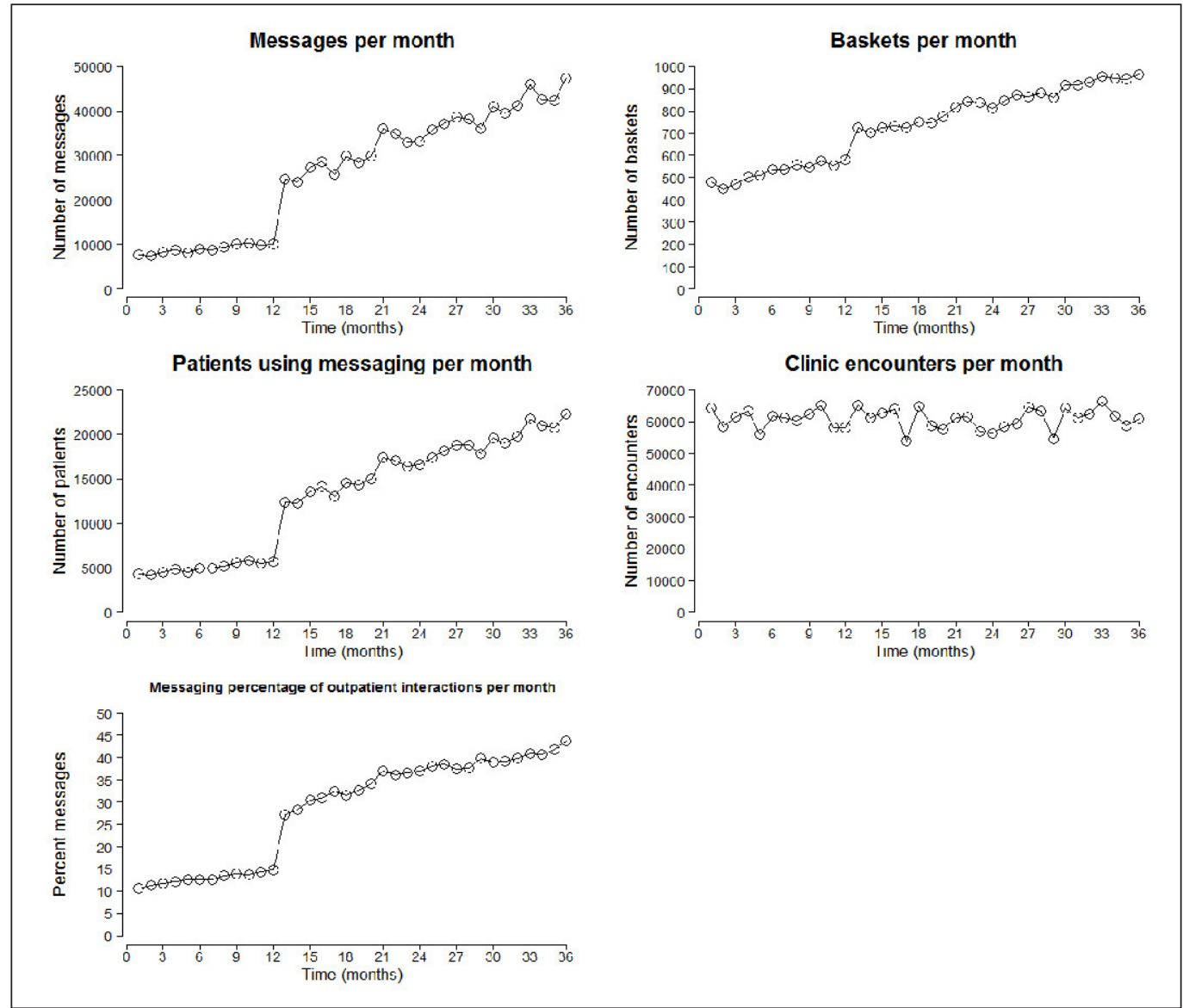

Fig. 1 Number of (A) message threads, (B) message baskets (C) patients using messaging, (D) outpatient clinic encounters, and $(E)$ the messaging percentage as a form of outpatient interaction per month. 


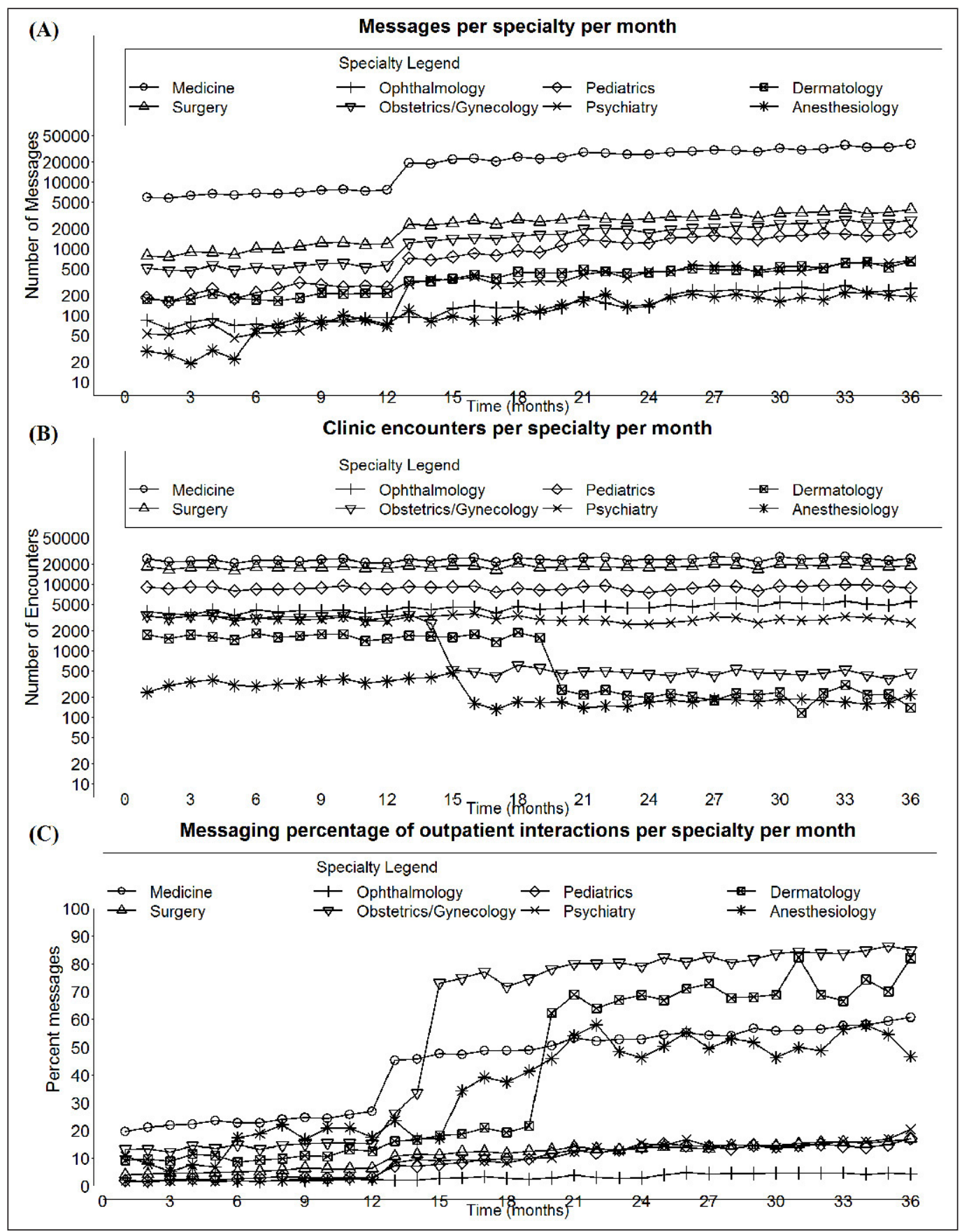

Fig. 2 Specialty usage of secure messaging. The plots below present the (A) total number of message threads, (B) the total number of outpatient clinic encounters and (C) messaging percentage of outpatient interactions per specialty per month. 


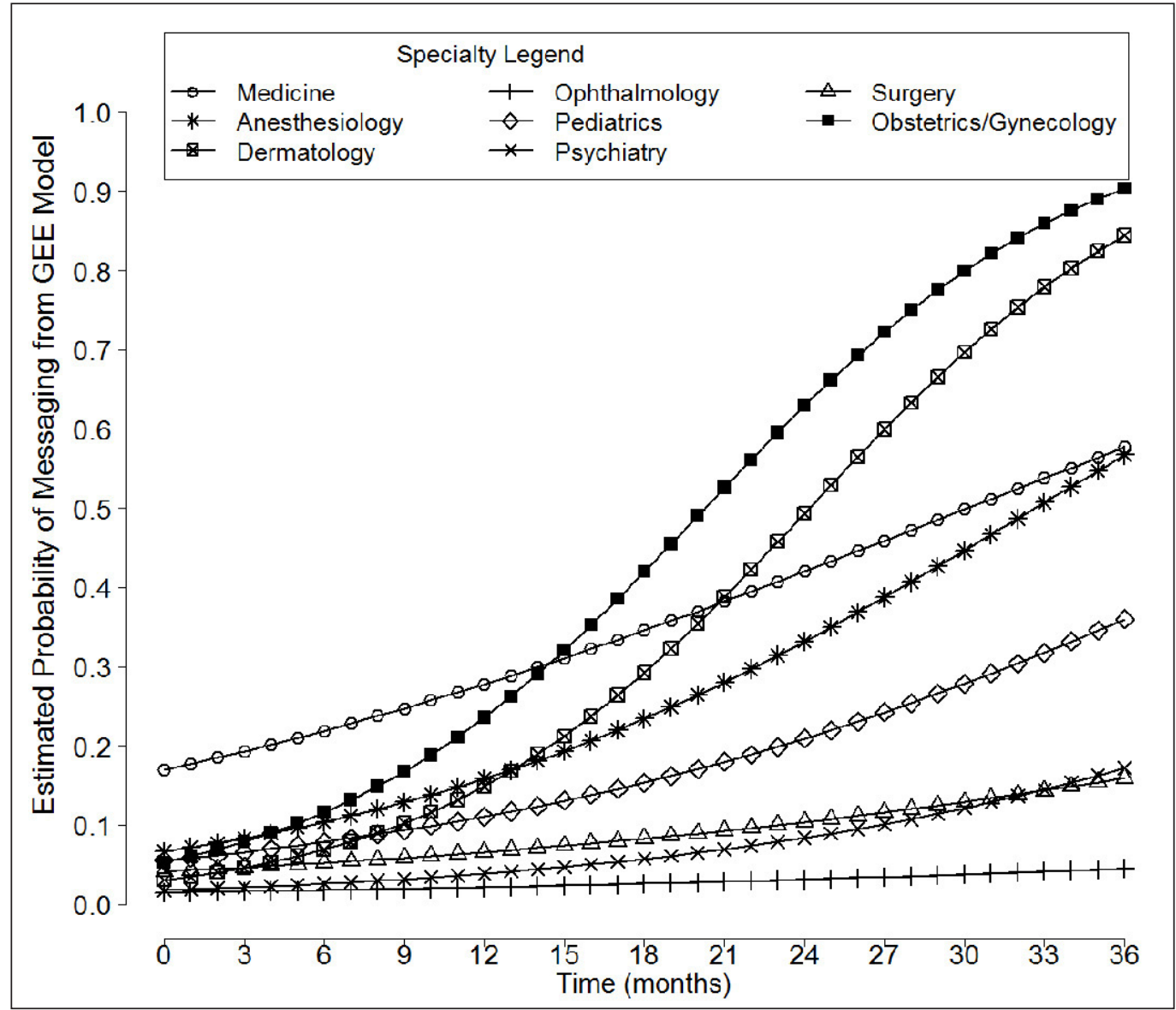

Fig. 3 This figure presents the generalized estimating equation with logit link in a plot of messaging probability by specialty. 
Table 1 Demographic and specialty distributions across outpatient interactions.

\begin{tabular}{|l|l|l|}
\hline & $\begin{array}{l}\text { Outpatient Encounters } \\
(\mathrm{N}=2,189,521)\end{array}$ & $\begin{array}{l}\text { Message Threads } \\
(\mathrm{N}=948,428)\end{array}$ \\
\hline Sex & & \\
\hline Female & $1,173,808(53.6 \%)$ & $607,683(64.1 \%)$ \\
\hline Male & $1,015,713(46.4 \%)$ & $340,745(35.9 \%)$ \\
\hline Race & & $769,485(81.1 \%)$ \\
\hline Caucasian & $1,499,126(68.5 \%)$ & $101,529(10.7 \%)$ \\
\hline Unknown & $288,257(13.2 \%)$ & $60,659(6.4 \%)$ \\
\hline African American & $300,839(13.7 \%)$ & $9,452(1.0 \%)$ \\
\hline Asian/Pac. Islander & $31,327(1.4 \%)$ & $6,319(0.7 \%)$ \\
\hline Hispanic/Latino & $66,410(3.0 \%)$ & $984(0.1 \%)$ \\
\hline American Indian/Inuit & $3,562(0.2 \%)$ & \\
\hline Age & & $50(35,60)$ \\
\hline Specialty & $46(18,61)$ & \\
\hline Medicine & & $742,454(78.3 \%)$ \\
\hline Surgery & $843,550(38.5 \%)$ & $84,001(8.9 \%)$ \\
\hline Obstetrics/Gynecology & $661,337(30.2 \%)$ & $53,424(5.6 \%)$ \\
\hline Pediatrics & $54,872(2.5 \%)$ & $33,543(3.5 \%)$ \\
\hline Dermatology & $318,386(14.5 \%)$ & $13,591(1.4 \%)$ \\
\hline Psychiatry & $34,785(1.6 \%)$ & $11,541(1.2 \%)$ \\
\hline Ophthalmology & $108,081(4.9 \%)$ & $5,393(0.6 \%)$ \\
\hline Anesthesiology & $159,818(7.3 \%)$ & $4,481(0.5 \%)$ \\
\hline & $8,692(0.4 \%)$ & \\
\hline & & \\
\hline
\end{tabular}

Table 2 This table presents the generalized estimating equation with logit link: initial and monthly change in odds ratios (OR) and $95 \%$ confidence intervals $(95 \% \mathrm{Cl})$, representing the odds of receiving a message by specialty.

\begin{tabular}{|l|l|l|}
\hline Specialty & OR $(95 \% \mathrm{CI})$ & \\
\hline Initial & Monthly Change \\
\hline Medicine & 1.00 (referent) & $1.05(1.05,1.05)$ \\
\hline Anesthesiology & $0.35(0.28,0.43)$ & $1.03(1.02,1.04)$ \\
\hline Pediatrics & $0.29(0.26,0.32)$ & $1.01(1.01,1.01)$ \\
\hline Obstetrics/Gynecology & $0.27(0.26,0.29)$ & $1.09(1.09,1.10)$ \\
\hline Surgery & $0.21(0.20,0.22)$ & $0.99(0.99,0.99)$ \\
\hline Dermatology & $0.15(0.13,0.18)$ & $1.09(1.09,1.10)$ \\
\hline Psychiatry & $0.09(0.08,0.10)$ & $1.02(1.01,1.02)$ \\
\hline Ophthalmology & $0.07(0.06,0.08)$ & $0.98(0.97,0.98)$ \\
\hline
\end{tabular}




\section{References}

1. Patient portal - Wikipedia, the free encyclopedia. [cited 2014 Sep 4]. Available from: http://en.wikipedia.org/wiki/Patient_portal

2. Archer N, Fevrier-Thomas U, Lokker C, McKibbon KA, Straus SE. Personal health records: a scoping review. J Am Med Inform Assoc JAMIA 2011; 18(4): 515-522.

3. HealthIT.gov. What is a patient portal? |FAQs | Providers \& Professionals | HealthIT.gov. 2014 [cited 2015 Feb 10]. Available from: http://www.healthit.gov/providers-professionals/faqs/what-patient-portal

4. Masys DR, Baker DB. Patient-Centered Access to Secure Systems Online (PCASSO): a secure approach to clinical data access via the World Wide Web. Proc Conf Am Med Inform Assoc AMIA Annu Fall Symp AMIA Fall Symp 1997; 340-343.

5. Gann B. Giving patients choice and control: health informatics on the patient journey. Yearb Med Inform 2012; 7(1): 70-73.

6. De Lusignan S, Mold F, Sheikh A, Majeed A, Wyatt JC, Quinn T, Cavill M, Gronlund TA, Franco C, Chauhan U, Blakey H, Kataria N, Barker F, Ellis B, Koczan P, Arvanitis TN, McCarthy M, Jones S, Rafi I. Patients' online access to their electronic health records and linked online services: a systematic interpretative review. BMJ Open 2014; 4(9): e006021.

7. Phelps RG, Taylor J, Simpson K, Samuel J, Turner AN. Patients' continuing use of an online health record: a quantitative evaluation of 14,000 patient years of access data. J Med Internet Res 2014; 16(10): e241.

8. Woywodt A, Vythelingum K, Rayner S, Anderton J, Ahmed A. Single-centre experience with Renal PatientView, a web-based system that provides patients with access to their laboratory results. J Nephrol 2014; 27(5): 521-527.

9. Murray J, Majeed A, Khan MS, Lee JT, Nelson P. Use of the NHS Choices website for primary care consultations: results from online and general practice surveys. JRSM Short Rep 2011; 2(7): 56.

10. Goldzweig CL, Orshansky G, Paige NM, Towfigh AA, Haggstrom DA, Miake-Lye I, Beroes JM, Shekelle PG. Electronic patient portals: evidence on health outcomes, satisfaction, efficiency, and attitudes: a systematic review. Ann Intern Med 2013; 159(10): 677-687.

11. Baer D. Patient-physician e-mail communication: the kaiser permanente experience. J Oncol Pract Am Soc Clin Oncol 2011; 7(4): 230-233.

12. Chen C, Garrido T, Chock D, Okawa G, Liang L. The Kaiser Permanente Electronic Health Record: transforming and streamlining modalities of care. Health Aff Proj Hope 2009; 28(2): 323-333.

13. Cimino JJ, Patel VL, Kushniruk AW. The patient clinical information system (PatCIS): technical solutions for and experience with giving patients access to their electronic medical records. Int J Med Inf 2002; 68(1-3): 113-127.

14. Earnest MA, Ross SE, Wittevrongel L, Moore LA, Lin C-T. Use of a patient-accessible electronic medical record in a practice for congestive heart failure: patient and physician experiences. J Am Med Inform Assoc 2004; 11(5): 410-417.

15. Goldzweig CL, Towfigh AA, Paige NM, Orshansky G, Haggstrom DA, Beroes JM, Miake-Lye I, Shekelle PG. Systematic Review: Secure Messaging Between Providers and Patients, and Patients' Access to Their Own Medical Record: Evidence on Health Outcomes, Satisfaction, Efficiency and Attitudes. Washington (DC): Department of Veterans Affairs (US); 2012 [cited 2015 Feb 13]. Available from: http://www.ncbi. nlm.nih.gov/books/NBK100359/

16. Grant RW, Wald JS, Schnipper JL, Gandhi TK, Poon EG, Orav EJ, Williams DH, Volk LA, Middleton B. Practice-linked online personal health records for type 2 diabetes mellitus: a randomized controlled trial. Arch Intern Med 2008; 168(16): 1776-1782.

17. Green BB, Cook AJ, Ralston JD, Fishman PA, Catz SL, Carlson J, Carrell D, Tyll L, Larson EB, Thompson RS. Effectiveness of home blood pressure monitoring, Web communication, and pharmacist care on hypertension control: a randomized controlled trial. JAMA 2008; 299(24): 2857-2867.

18. Liederman EM, Lee JC, Baquero VH, Seites PG. Patient-physician web messaging. The impact on message volume and satisfaction. J Gen Intern Med 2005; 20(1): 52-57.

19. Shapochka A. Providers Turn to Portals to Meet Patient Demand, Meaningful Use | Journal of AHIMA. [cited 2014 Sep 30]. Available from: http://journal.ahima.org/2012/08/23/providers-turn-to-portals-tomeet-patient-demand-meaningful-use/

20.RCGP-Road-Map. [cited 2014 Nov 12]. Available from: http://www.rcgp.org.uk/ /media/Files/CIRC/ POA/RCGP-Road-Map.ashx

21.The power of information: Putting all of us in control of the health and care information we need. [cited 2014 Nov 12]. Available from: https://www.gov.uk/government/uploads/system/uploads/attach ment_data/file/213689/dh_134205.pdf 
22.Equity and excellence: Liberating the NHS. [cited 2014 Dec 2]. Available from: https://www.gov.uk/gov ernment/uploads/system/uploads/attachment_data/file/216664/dh_129580.pdf

23. Tang $\mathrm{CH}$, Li CC, Chang GH, Chang P. Implementing a personalized portal combined with workflow management tools used in diabetes care. AMIA Annu Symp Proc 2003; 1026.

24. Quinn CC, Clough SS, Minor JM, Lender D, Okafor MC, Gruber-Baldini A. WellDoc mobile diabetes management randomized controlled trial: change in clinical and behavioral outcomes and patient and physician satisfaction. Diabetes Technol Ther 2008; 10(3): 160-168.

25. Nordqvist C, Hanberger L, Timpka T, Nordfeldt S. Health professionals' attitudes towards using a Web 2.0 portal for child and adolescent diabetes care: qualitative study. J Med Internet Res 2009; 11(2): e12.

26. Ma C, Warren J, Phillips P, Stanek J. Empowering patients with essential information and communication support in the context of diabetes. Int J Med Inf 2006; 75(8): 577-596.

27. Bryce CL, Zickmund S, Hess R, McTigue KM, Olshansky E, Fitzgerald K, Fischer G. Value versus user fees: perspectives of patients before and after using a web-based portal for management of diabetes. Telemed J E-Health Off J Am Telemed Assoc 2008; 14(10): 1035-1043.

28. Hess R, Bryce CL, Paone S, Fischer G, McTigue KM, Olshansky E, Zickmund S, Fitzgerald K, Siminerio L. Exploring challenges and potentials of personal health records in diabetes self-management: implementation and initial assessment. Telemed J E-Health Off J Am Telemed Assoc 2007; 13(5): 509-517.

29. Agrawal A, Mayo-Smith MF. Adherence to computerized clinical reminders in a large healthcare delivery network. Stud Health Technol Inform 2004; 107(Pt 1): 111-114.

30. Grant RW, Wald JS, Poon EG, Schnipper JL, Gandhi TK, Volk LA, Middleton B. Design and implementation of a web-based patient portal linked to an ambulatory care electronic health record: patient gateway for diabetes collaborative care. Diabetes Technol Ther 2006; 8(5): 576-586.

31.McCarrier KP, Ralston JD, Hirsch IB, Lewis G, Martin DP, Zimmerman FJ, Goldberg HI. Web-based collaborative care for type 1 diabetes: a pilot randomized trial. Diabetes Technol Ther 2009; 11(4): 211-217.

32. Ralston JD, Hirsch IB, Hoath J, Mullen M, Cheadle A, Goldberg HI. Web-based collaborative care for type 2 diabetes: a pilot randomized trial. Diabetes Care 2009; 32(2): 234-239.

33. Sarkar U, Lyles CR, Parker MM, Allen J, Nguyen R, Moffet HH, Schillinger D, Karter AJ. Use of the Refill Function Through an Online Patient Portal is Associated With Improved Adherence to Statins in an Integrated Health System. Med Care 2014; 52(3): 194-201.

34. Grant RW, Wald JS, Schnipper JL, Gandhi TK, Poon EG, Orav EJ, Williams DH, Volk LA, Middleton B. Practice-linked online personal health records for type 2 diabetes mellitus: a randomized controlled trial. Arch Intern Med 2008; 168(16): 1776-1782.

35. Earnest MA, Ross SE, Wittevrongel L, Moore LA, Lin C-T. Use of a patient-accessible electronic medical record in a practice for congestive heart failure: patient and physician experiences. J Am Med Inform Assoc 2004; 11(5): 410-417.

36. Ross SE, Moore LA, Earnest MA, Wittevrongel L, Lin C-T. Providing a web-based online medical record with electronic communication capabilities to patients with congestive heart failure: randomized trial. J Med Internet Res 2004; 6(2): e12.

37.Epstein JN, Langberg JM, Lichtenstein PK, Kolb R, Simon JO. The myADHDportal.com Improvement Program: An innovative quality improvement intervention for improving the quality of ADHD care among community-based pediatricians. Clin Pract Pediatr Psychol 2013; 1(1): 55-67.

38. Osborn CY, Mayberry LS, Wallston KA, Johnson KB, Elasy TA. Understanding patient portal use: implications for medication management. J Med Internet Res 2013; 15(7): e133.

39. Grant RW, Wald JS, Poon EG, Schnipper JL, Gandhi TK, Volk LA, Middleton B. Design and implementation of a web-based patient portal linked to an ambulatory care electronic health record: patient gateway for diabetes collaborative care. Diabetes Technol Ther 2006; 8(5): 576-586.

40.40. Schnipper JL, Gandhi TK, Wald JS, Grant RW, Poon EG, Volk LA, Businger A, Siteman E, Buckel L, Middleton B. Design and implementation of a web-based patient portal linked to an electronic health record designed to improve medication safety: the Patient Gateway medications module. Inform Prim Care 2008; 16(2): 147-155.

41. Collmann J, Cooper T. Breaching the security of the Kaiser Permanente Internet patient portal: the organizational foundations of information security. J Am Med Inform Assoc 2007; 14(2): 239-243.

42. Carrell D, Ralston JD. Variation in adoption rates of a patient web portal with a shared medical record by age, gender, and morbidity level. AMIA Annual Symposium Proceedings. American Medical Informatics Association 2006: 871.

43. Nazi KM, Woods SS. MyHealtheVet PHR: a description of users and patient portal use. AMIA. Annual Symposium proceedings/AMIA Symposium AMIA Symposium 2007: 1182-1182. 
44.Epstein JN, Langberg JM, Lichtenstein PK, Kolb R, Altaye M, Simon JO. Use of an Internet portal to improve community-based pediatric ADHD care: a cluster randomized trial. Pediatrics 2011; 128(5): e1201-e1208.

45. Ketterer T, West DW, Sanders VP, Hossain J, Kondo MC, Sharif I. Correlates of patient portal enrollment and activation in primary care pediatrics. Acad Pediatr 2013; 13(3): 264-271.

46. North F, Crane SJ, Chaudhry R, Ebbert JO, Ytterberg K, Tulledge-Scheitel SM, Stroebel RJ. Impact of patient portal secure messages and electronic visits on adult primary care office visits. Telemed J E-Health Off J Am Telemed Assoc 2014; 20(3): 192-198.

47.Jung C, Padman R, Shevchik G, Paone S. Who are portal users vs. early e-Visit adopters? A preliminary analysis. AMIA Annu Symp Proc AMIA Symp 2011; 2011: 1070-1079.

48. Hanberger L, Ludvigsson J, Nordfeldt S. Use of a web 2.0 portal to improve education and communication in young patients with families: randomized controlled trial. J Med Internet Res 2013; 15(8): e175.

49. Cho AH, Arar NH, Edelman DE, Hartwell PH, Oddone EZ, Yancy WS Jr. Do diabetic veterans use the Internet? Self-reported usage, skills, and interest in using My HealtheVet Web portal. Telemed J E-Health Off J Am Telemed Assoc 2010; 16(5): 595-602.

50.Tsai J, Rosenheck RA. Use of the internet and an online personal health record system by US veterans: comparison of Veterans Affairs mental health service users and other veterans nationally. J Am Med Inform Assoc JAMIA 2012; 19(6): 1089-1094.

51. Burke RP, Rossi AF, Wilner BR, Hannan RL, Zabinsky JA, White JA. Transforming patient and family access to medical information: utilisation patterns of a patient-accessible electronic health record. Cardiol Young 2010; 20(5): 477-484.

52. Tuil WS, Verhaak CM, Braat DDM, de Vries Robbé PF, Kremer JAM. Empowering patients undergoing in vitro fertilization by providing Internet access to medical data. Fertil Steril 2007; 88(2): 361-368.

53. Weingart SN, Rind D, Tofias Z, Sands DZ. Who uses the patient internet portal? The PatientSite experience. J Am Med Inform Assoc 2006; 13(1): 91-95.

54.Haun JN, Lind JD, Shimada SL, Martin TL, Gosline RM, Antinori N, Stewart M, Simon SR. Evaluating user experiences of the secure messaging tool on the Veterans Affairs' patient portal system. J Med Internet Res 2014; 16(3): e75.

55.Barnett TE, Chumbler NR, Vogel WB, Beyth RJ, Qin H, Kobb R. The effectiveness of a care coordination home telehealth program for veterans with diabetes mellitus: a 2-year follow-up. Am J Manag Care 2006; 12(8): 467-474.

56.Stiles RA, Deppen SA, Figaro MK, Gregg WM, Jirjis JN, Rothman RL, Johnston PE, Miller RA, Dittus RS, Speroff T. Behind-the-scenes of patient-centered care: content analysis of electronic messaging among primary care clinic providers and staff. Med Care 2007; 45(12): 1205-1209.

57. Osborn CY, Rosenbloom ST, Stenner SP, Anders S, Muse S, Johnson KB, Jirjis J, Jackson GP. MyHealthAtVanderbilt: policies and procedures governing patient portal functionality. J Am Med Inform Assoc. 2011; 18 (Suppl. 1): i18-i23.

58. Allphin M. Patient Portals 2013: On Track for Meaningful Use? KLAS research; 2013 Aug [cited 2004 Sep 17]. Available from: https://www.klasresearch.com/store/ReportDetail.aspx?Productid=844

59. White CB, Moyer CA, Stern DT, Katz SJ. A content analysis of e-mail communication between patients and their providers: patients get the message. J Am Med Inform Assoc 2004; 11(4): 260-267.

60. Hobbs J, Wald J, Jagannath YS, Kittler A, Pizziferri L, Volk LA, Middleton B, Bates DW. Opportunities to enhance patient and physician e-mail contact. Int J Med Inf 2003; 70(1): 1-9.

61. McDaniel LS, Henderson NC, Rathouz PJ. Fast Pure R Implementation of GEE: Application of the Matrix Package. R J 2013; 5(1): 181-187.

62. Wallwiener M, Wallwiener CW, Kansy JK, Seeger H, Rajab TK. Impact of electronic messaging on the patient-physician interaction. J Telemed Telecare 2009; 15(5): 243-250.

63. Crotty BH, Tamrat Y, Mostaghimi A, Safran C, Landon BE. Patient-To-Physician Messaging: Volume Nearly Tripled As More Patients Joined System, But Per Capita Rate Plateaued. Health Aff (Millwood) 2014; 33(10): 1817-1822.

64.Stage2_MeaningfulUseSpecSheet_TableContents_EPs. [cited 2014 Nov 12]. Available from: http://www. cms.gov/Regulations-and-Guidance/Legislation/EHRIncentivePrograms/Downloads/Stage2_MeaningfulUseSpecSheet_TableContents_EPs.pdf

65. Blumenthal D, Tavenner M. The "meaningful use" regulation for electronic health records. N Engl J Med 2010; 363(6): 501-504.

66. Roter DL, Larson S, Sands DZ, Ford DE, Houston T. Can e-mail messages between patients and physicians be patient-centered? Health Commun 2008; 23(1): 80-86.

67.Zhou YY, Garrido T, Chin HL, Wiesenthal AM, Liang LL. Patient access to an electronic health record with secure messaging: impact on primary care utilization. Am J Manag Care 2007; 13(7): 418-424. 
68. Palen TE, Ross C, Powers JD, Xu S. Association of online patient access to clinicians and medical records with use of clinical services. JAMA 2012; 308(19): 2012-2019.

69. Simon GE, Ralston JD, Savarino J, Pabiniak C, Wentzel C, Operskalski BH. Randomized trial of depression follow-up care by online messaging. J Gen Intern Med 2011; 26(7): 698-704.

70. Katz SJ, Moyer CA, Cox DT, Stern DT. Effect of a triage-based E-mail system on clinic resource use and patient and physician satisfaction in primary care: a randomized controlled trial. J Gen Intern Med 2003; 18(9): 736-744.

71.Lin C-T, Wittevrongel L, Moore L, Beaty BL, Ross SE. An Internet-based patient-provider communication system: randomized controlled trial. J Med Internet Res 2005; 7(4): e47.

72.2014 proposed Medicare Physician Fee Schedule - American Academy of Family Physicians (AAFP). [cited 2014 Sep 4]. Available from: http://www.aafp.org/dam/AAFP/documents/advocacy/payment/medi care/ES-2014ProposedFeeSchedule-071913.pdf

73. Wade-Vuturo AE, Mayberry LS, Osborn CY. Secure messaging and diabetes management: experiences and perspectives of patient portal users. J Am Med Inform Assoc 2013; 20(3): 519-525. 